\title{
Jeffrey D. Brison \\ Rockefeller, Carnegie and Canada: American Philanthropy and the Arts and Letters in Canada.
}

Montreal and Kingston: McGill-Queen's University Press, 2005. xiii, 281 pp.

\author{
Allan Smith \\ University of British Columbia
}

Up to the 1900s, accounts of Canada's cultural development simultaneously varied and stayed the same. Change was evident in regular alteration of interpretive frameworks. Nineteenth century commentators used an essentially romantic focus to fix on cultural development as the final stage in a process of growth and maturation carrying the community forward to a full flowering of its moral and intellectual capacities. Later, an emphasis on policy and state-building produced stress on institutions and organizational foundations. Later still, orientations to technology brought strong concern about media systems, mass communication, and cultural homogenization. Towards the end of the twentieth century, understanding of society as a complicated assemblage of class, gender, cultural, ethnic and other formations generated attention to cultural activity's relation to group identities, group interactions, and the meaning of complex social wholes. Continuity, for its very considerable part, manifested itself in the fact that - even as these changing views jostled for position - certain general assumptions remained consistently in play. There was an ongoing belief that Canada's culture — like cultures at large — was, or was in the process of becoming, a bounded, identifiable, delimited phenomenon open to definition in terms that, once established, would be constant and set; Canada, its composition complete, would emerge as "British," or "North American," or "northern," or "bilingual," or "multicultural," in some final way. Accompanying this idea was an equally strong notion that the business of identity — growth and stabilization - was under continuing threat from the penetration of US cultural influences. Co-existing with that concern, finally, was the conviction that responses to the US danger needed to have-and, indeed, did have — an explicit, focused, direct, structured, policy-based, state-centered character of the sort represented by such institutions as the Canadian Broadcasting 
Corporation, the National Film Board, and the Canada Council.

The recent past has seen change continue in the first area and move strongly into position in the second. Under the influence of post-colonial theory, subaltern studies, and developments in the investigation of cultural dynamics generally, analysts of the Canadian situation have, in fact, challenged the old verities in a fundamental way. Notions of culture as a stable, bounded phenomenon have come under particularly strong attack. Canadian culture remains an object of study, but as an entity to be seen as fluid, dialogically — produced and shaped by continuous interaction between outlooks generated within local contexts and influences entering from the world at large. The idea that external derivations are unassailably strong has, accordingly, also changed; local patterns of belief, response, and attitude are viewed — again, as elsewhere - as altogether capable of domesticating what enters their domain even as they themselves are changed by their encounters with it. The state's place has altered too: resistance to and domestication of general influences may, analysts insist, involve state action, but do not have to; since it is the local culture itself that mediates the elements with which it is in contact, that mediation is what is fundamental; public policy becomes nothing more than one of the forms it may take.

Evident in the study of Canada's popular culture - Flaherty and Manning's The Beaver Bites Back? (1993) is a key document — and present as well in examination of literary and other endeavours - Mount's When Canadian LIterature Moved to New York (2005) stands as a major contribution - this revolution in outlook is now affecting consideration of cultural institutions and agencies. Focusing on the substantial Canadian work of the Carnegie and Rockefeller Foundations in the first half of the twentieth century, the book here under review is a case in point. The book wastes no time stating what it sees at issue. Adopting arguments developed by Clyde Barrow, Kathleen McCarthy, and others, it supports the view that the foundations were functionally implicated in the consolidation and spread of social values, organizational imperatives, disciplinary emphases, and instrumentalist understandings associated with corporate America's ascendancy in the United States. That step taken, it proceeds to the claim that in extending their reach into other countries - Canada, of course included - they were necessarily involved in a projecting abroad of those same norms and standards, and therefore in activity that can only be described as a form of "cultural imperialism." 1

Since, however, their work outside the United States - Canada again included - had to be done through local agents, matters were not straightforward; the locals, indeed, exercised some real control over what was happening and so insured that such cultural power as was being exercised did not get used "in the fullest sense." 2 What, instead, developed was a situation in which foundation officials in the United States "worked ... to pursue their own agenda in Canada" while Canadians "harnessed and mediated American support to further [their] particular agenda." ${ }^{3}$ Something like Dipesh Chakrabarty's system of "conjoined and disjunctive" elements entered into play; more than a trace of Ranajit Guha's "dominance without hegemony" appeared; Canadians were at once implicated in a larger framework and able to use the resources — intellectual and material — that framework provided to advance their 
own interests. The complicated exchanges between Canadians and Americans that all this produced are examined in detail. The results these yielded in public health, medical education, support for local and regional art organizations, funding of university extension work, and organization of cultural conferences receive solid attention. The research funding given the projects in which such figures as Harold Innis, Donald Creighton, and A.R.M. Lower were involved is discussed at length. Though, in consequence, fundamental impulses are seen to have remained broadly hegemonic - getting smooth functioning in a spreading liberal/capitalist system continued as the goal - matters are presented as having played out in ways that were decidedly rough-grained and particularism-recognizing.

The book's revisiting of dominations' dynamics is basic; so also is its assessment of statism's position. Since the activity here considered, including the "resistance" it offered to US domination, occurred without state support, statism appears as rather less than central to Canada's cultural story, and perhaps to the Canadian story in general; the book "interrogates and transcends...the border between the 'private' and the 'public' spheres" ${ }^{4}$ and finds it less fixed and clear than had once been thought.

Not all the difficulties involved in analysis of this sort have been avoided. Theory and concepts are applied mechanically. Passages meant to denote ambiguity instead suggest that the argument is not under full control. That argument is in any case often made by assertion. Counter positions - those of S.M. Lipset especially - are caricatured. Earlier work in the area has not always been used effectively; sometimes it has not been used at all. The reader is left to perform too much of the sense-making labour that the book itself should be carrying out. This said, the book repays the time spent with it. The data are full and complete, the conceptual framework (for all the awkwardness with which it is structured) timely and appropriate, the book open to assessment as a manifestation of current concerns. One learns from it even while wishing it displayed more mastery, not over ambivalence, but over its demonstration of its claim - echoing Gyan Prakash and others - that such mastery is impossible.

\section{Notes}

1 Jeffry D. Brisson, Rockefeller, Carnegie and Canada: American Philanthropy and the Arts and Letters in Canada (Montreal: McGill-Queen's University Press, 2005), 9.

2 Ibid., 10.

3 Ibid., 15.

4 Ibid., 8. 